\section{CARACTERIZACIÓN DE LA METALURGIA INICIAL GALLEGA: UNA REVISIÓN}

\author{
EARLY GALICIAN METALWORK \\ (NORTH-WEST SPAIN): A REVIEW
}

\section{BEATRIZ COMENDADOR REY (*)}

In my bed I read my mind remember how the mice were blind I'll watch them fighting in their cage Could this be the Plastic Age?

(BUGGLES. «The Age of Plastic»)

\section{RESUMEN}

Ninguno de los varios intentos previos de establecer un marco cronológico para las primeras piezas metálicas gallegas ha resultado totalmente satisfactorio. La metalurgia ha sido considerada en términos de tradiciones e industrias pobremente definidas y la terminología convencional ha tendido a encorsetar excesivamente los objetos. Un nuevo estudio contextual de este conjunto suscita replanteamientos sobre la articulación de la metalurgia con la cerámica campaniforme y el Bronce Antiguo, la cronología de aparición de la aleación binaria $\mathrm{Cu}$ $\mathrm{Sn}$, o el origen argárico de las espirales de plata en el Noroeste de la Península Ibérica.

\section{ABSTRACT}

Many attempts have been made to establish a chronological framework for Galician early metalwork, and none is wholly satisfactory. Metal-working has been seen in

(*) Becaria Predoctoral en la Universidad de Santiago. Facultad de Geografía e Historia. Departamento de Historia I. Área de Prehistoria. Pza. Universidade. 15703 Santiago.

El artículo fue remitido en su versión final el 13-IX-95. terms of poorly defined traditions and industries, and the conventional terminology has tended to straitjacket the artefacts themselves. Through the contextual study of that set new outlines are proposed on the articulation of the metalwork with Bell Beaker pottery and the Early Bronze Age, the beginnings of the copper-tin alloy, or the argaric origin of silver spirals in the North-West of the Iberian Peninsula.

Palabras clave: Galicia. Metalurgia. Calcolítico. Bronce Antiguo. Campaniforme.

Key words: North-west Spain. Metallurgy. Chalcolithic. Early Bronze Age. Bell Beaker.

\section{LA PRIMERA METALURGIA GALLE- GA: ESTADO DE LA CUESTIÓN}

Varios son los problemas que impiden una buena caracterización tanto de la aparición de la tecnología metalúrgica en Galicia, como de su contexto cultural de desarrollo. La documentación en el ámbito doméstico se reduce a escasos elementos del proceso de elaboración, por lo que el estudio se limita casi exclusivamente a objetos procedentes del mundo funerario, don- 
de la muestra es mayor a pesar de haber estado sometida a continuos saqueos centrados especialmente en los objetos metálicos. Por otro lado, el desconocimiento de las circunstancias de muchos de los hallazgos y/o la precaria información recogida dificulta su contextualización.

Ya en un ámbito más amplio, la indefinición de los yacimientos del Bronce Inicial respecto a los del Calcolítico y la escasez de dataciones. complican aún más su adscripción cultural.

La problemática articulación de la metalurgia con el "Fenómeno Tumular" en el Noroeste no deriva tanto del registro de las piezas, como de la complejidad de este fenómeno sepulcral de múltiples manifestaciones. El término «fenómeno tumular» atiende a la presencia, al menos en origen, de un túmulo de cubrición que constituye el único elemento común de una serie de enterramientos de gran diversidad estructural (1). Además de esta definición que incide en sus aspectos arquitectónicos, otras de las más recientes valoran su intención de monumentalidad, a través de la que diversas comunidades afirmarían de modo visible su presencia (Fábregas y Ruiz-Gálvez, 1994: 145). Sin embargo se ha señalado que la apariencia uniforme de los túmulos debe ser entendida como la de «arquitecturas arqueológicas alejadas en mayor o menor grado, de un estado original alterado durante el proceso de construcción del yacimiento" (Vaquero, 1993: 39). En cuanto a su duración, como han puesto de manifiesto algunos autores, si bien hasta hace poco se daba por concluido hacia el 1800 a.C., coincidiendo de forma aproximada con la aparición de las cistas rectangulares sepultadas bajo tierra, en años recientes comienza a defenderse su persistencia (Fábregas y Ruiz-Gálvez, 1994: 146). Aunque es problemático, se suele considerar que un menor tamaño de los monumentos y una visibilidad menor sobre el entorno denota una cronología más tardía, en la transición III-II milenio a.C., en relación con el supuesto paso de enterramientos colectivos y diacrónicos, a enterramientos individuales.

De este segundo tipo se consideran las cistas, cajas de piedras de mediano tamaño utilizadas como tumbas y generalmente sepultadas bajo tierra, cuyos «ajuares» se presuponen unipersonales y de deposición sincrónica. La falta de

(1) En este trabajo designamos «túmulo» sólo a los monumentos con túmulo. túmulo o de cualquier otro elemento (quizás no conservado), sugiere un menor interés por hacer visible el enterramiento. De hecho la mayor parte de los hallazgos de cistas son casuales y han estado menos sometidas a los saqueos. En general han sido planteadas como el enterramiento típico del Bronce Antiguo (Vázquez, 1980), aunque hasta el momento no han sido objeto de un trabajo exhaustivo que aborde su problemática. Por todas estas circunstancias es difícil el establecimiento de comparaciones con los contextos tumulares.

Un aspecto especialmente problemático en Galicia es la relación de la metalurgia con el "Fenómeno Campaniforme». El tema de la cerámica campaniforme en Galicia, tratado globalmente (Vázquez y Criado, 1980), precisa de una nueva síntesis que incluya recientes resultados y actualice el estado de la cuestión. Por ejemplo, respecto al período de vigencia de la cerámica campaniforme (o de tradición campaniforme), últimamente se ha defendido incluso hasta finales del II milenio a.C., lo que supone un marco cronológico más amplio que el tradicionalmente aceptado (Prieto, 1993: 21) (2).

Diversos autores han defendido la vinculación entre el fenómeno campaniforme y el desarrollo de la metalurgia también en el Noroeste (Monteagudo, 1953; Vázquez, 1992: 51; Comendador, 1991-2: 198). Del mismo modo, se acepta la existencia de una tradición metalúrgica campaniforme, o con un fuerte sustrato campaniforme durante el Bronce Antiguo (Sierra, 1976: 213; Ruiz-Gálvez, 1984: 223). Sin embargo, ninguno de estos autores caracteriza esta metalurgia, a excepción de alusiones de Sierra (1976: 213) a una metalurgia de cobre sin alear y de cobre arseniado. Por su parte Ruiz-Gálvez (1984: 335), que recoge escasos y heterogéneos análisis, reconoce las limitaciones de sus observaciones sobre la tecnología metalúrgica.

Rovira y Montero (1994: 137-171) estiman que no es correcto hablar de una metalurgia campaniforme definida por sí misma y de aplicación general, sino de metalurgias asociadas al fenómeno campaniforme que evolucionan territorialmente de manera diferente en función de cada sociedad (3), lo que pone de relieve la necesidad de replantear sobre una base más sóli-

(2) Suárez (1993) considera que perdura no sólo más allá de sus límites cronológicos, sino también culturales.

(3) Susana Jorge (1986) sugiere ya este aspecto para el Noroeste de la Península Ibérica. 
da las consideraciones cronológicas sobre «tipos» de metalurgias.

En Galicia, desde el punto de vista tecnológico, los estudios son muy limitados y carecen de una base analítica cuantiosa y de calidad, principalmente por su heterogeneidad. El corpus más amplio publicado es el de los análisis de tipo compositivo realizados por el equipo de Stuttgart (Junghans et alii, 1968), que muestran, como tendencia general, presencias altas de arsénico, así como trazas de otras impurezas como antimonio, plata o hierro. Harrison y Craddock (1981: 162) defienden la aleación intencional de arsénico.

En relación con la interpretación de estos resultados, un aspecto que no ha sido suficientemente estudiado es el de la caracterización mineralógica del Noroeste desde un punto de vista «no industrial», orientada a una aproximación sobre accesibilidad de los recursos mineros en la Prehistoria. Son destacables los trabajos de Monteagudo (1954: 70-71) sobre minería, que sugieren la existencia de criaderos de cobre en Galicia de fácil beneficio. En una introducción a este tema (Comendador, 1993), y frente a la creencia en una escasa presencia de minerales de cobre en Galicia, concluimos que, si se valoran criterios no industriales, el cobre gallego habría bastado perfectamente para abastecer las necesidades de esta primera metalurgia. Lo mismo ocurre con otros minerales considerados foráneos, como la variscita.

Respecto a la caracterización de estos recursos de cobre, hasta el momento contamos con datos muy fragmentarios, pero hay una clara tendencia a la asociación con minerales de arsénico (pirrotina, mispiquel) en la zona central y norte de Galicia, y con arsénico y oro en el sur de la provincia de Pontevedra, por lo que las presencias de arsénico pueden ser debidas a la propia composición de las menas que se están explotando.

Ya por último, en relación con la tecnología de fabricación y acabado de las piezas, la ausencia de metalografías, de momento, no permite aproximaciones certeras para la mayor parte del conjunto.

Todo ello nos lleva a concluir que, hasta el presente, la producción metalúrgica que hemos estudiado carece de caracterización tecnológica.

Sin embargo, el establecimiento del Bronce Antiguo en el Noroeste se ha venido definiendo por la disociación entre la cerámica campani- forme y las industrias metálicas «propias». De este modo, especialmente los puñales de lengüeta (largos y puñales-espada) han sido por lo general incluidos en los inicios de la Edad del Bronce (Ruiz-Gálvez, 1979: 52), en lo que Harrison (1974: 85) denominó "Horizonte Montelavar» cuya definición excluiría a un buen número de ajuares gallegos que no cumplen la condición de que se asocien un puñal y al menos dos puntas del tipo "Palmela" en enterramientos individuales sin cerámica campaniforme. Harrison los incluye bajo el epígrafe de «hallazgos relacionados» o "grupo intermedio». Varios autores han argumentado tanto en contra de la disociación metal/cerámica campaniforme en el registro (al menos en un determinado momento del campaniforme), como de la propia construcción del «Horizonte Montelavar», en Galicia (Criado y Vázquez, 1980: 12,62) y en el Norte de Portugal (Jorge, 1986: 876-877).

En términos generales, la Prehistoria gallega ha utilizado la metalurgia como elemento diagnóstico aislado para solventar algunos de problemas que tiene planteados. Ahora precisamos observar qué ocurre cuando el proceso es a la inversa, y se pretende estudiar la metalurgia recurriendo a sus contextos.

\section{ORDENACIÓN DEL REGISTRO ARQUEOLÓGICO: UN NUEVO INTENTO DE CONTEXTUALIZACIÓN}

Con el objetivo de contextualizar la primera metalurgia gallega, hemos recopilado (4) un total de 163 objetos, procedentes de 82 Puntos Arqueológicos (PAs) (5), estudiando las prime-

(4) El «Catálogo de piezas metálicas gallegas relativas a los inicios de la metalurgia» se realizó con la colaboración de la D.X.P.H. de la Xunta de Galicia. Había sido en cierto modo comenzado en tres memorias de licenciatura defendidas en la Universidad de Santiago en 1991: A. Balseiro (1994): «Orfebrería prerromana en la provincia de Lugo». Diputación Provincial. Lugo; B. Comendador, «Los inicios de la metalurgia en la provincia de Pontevedra» (inédita) y N. Reboredo, “Orfebrería perromana en la provincia de La Coruña” (inédita).

Al mismo tiempo iniciamos la colaboración con el proyecto de investigación «Arqueometalurgia de la Península Ibérica: Tecnología y Cambio Cultural durante la Edad del Bronce» (DGCYT PB92-0315). De modo personal, y lamentablemente póstumo a su fallecimiento, quisiera agradecer a M. Fernández-Miranda la confianza que depositó en mí al admitirme como colaboradora del mencionado proyecto.

(5) Como un número importante de piezas están descontextualizadas, recogemos el concepto de Punto Arqueoló- 
ras producciones metálicas (o piezas relativas al proceso de su elaboración) en cobre, oro y plata, así como algunas de las primeras aleaciones binarias (bronce, posibles cobres arsenicales), importadas o de producción autóctona (Tabla 1). Es destacable, en relación a la distribución geográfica de estos PAs, el vacío existente en las sierras orientales y surorientales de Galicia con las cotas más elevadas, pero también con los recursos cupríferos más abundantes y accesibles, que contrasta con su presencia en las regiones costeras occidentales, en la zona central de Galicia y en la zona de A Terra Chá (Fig. 1).

\begin{tabular}{||l|c|c|}
\hline Provincia. & PAs \% & O \% \\
\hline A Coruña & 33 & 27 \\
\hline Pontevedra & 31 & 46 \\
\hline Lugo & 20,5 & 12,3 \\
\hline Ourense & 8,5 & 4 \\
\hline Descon. & 7 & 3.7 \\
\hline
\end{tabular}

Tabla 1. Distribución del porcentaje de puntos arqueológicos (PAs) con metal y del de los correspondientes objetos $(\mathrm{O})$ por provincias gallegas.

Clasificamos la muestra estructurando el conjunto en cinco grupos morfofuncionales (Montero, 1994: 53-61) (6). Cada uno de ellos está formado por diversos tipos (7) (Figs. 2 a 4).

Además hemos revisado las circunstancias de los descubrimientos de las piezas con el objetivo de constatar tendencias o posibles irregularida-

gico (PA) (Criado et alii, 1991: 60-61) como aquellos puntos en el espacio de trabajo en los que aparece material arqueológico (metálico).

(6) Grupo 1 Herramientas; Grupo 2 Herramientas o armas; Grupo 3 Armas; Grupo 4 Adornos y Objetos de Complemento; 5 Elementos del proceso de elaboración. En la clasificación de Montero, el Grupo 4 engloba Adornos y el 5 Objetos de Complemento o Accesorios.

(7) Grupo: 1 Punzones; Grupo 2: Hachas planas, Puñales, Puntas de flecha; Grupo 3 Alabardas y Puñales alabardados, Puñales-espada; Grupo 4: Joyas de tiras, Pulseras, Diademas simples, Peine, Espirales, Cadenas de Espirales, Láminas, Cilindros, Cuencos, Jarras, Barras abiertas y cerradas; Grupo 5: Preforma de producción, Gotas, Moldes, Fragmentos de crisoles. des en su contextualización (Tablas 2 y 3 ), conscientes de que este estudio de la/s metalurgia/s no deja de ser un aspecto parcial de la/s sociedad/es correspondientes.

Las particularidades de las relaciones entre los distintos grupos/clases/tipologías y los contextos quedan parcialmente resumidas en las tablas 4 y 5 .

\subsection{Contextos funerarios}

\subsection{1. "Tesouros dos mouros" guardados en túmulos}

Hemos constatado la presencia de metal en los siguientes tipos de túmulos: con cámara ortostática interna, sin cámara ortostática aparente, indefinidos, y fosa bajo túmulo.

- Túmulos con cámara ortostática interna: Las referencias para el análisis de estos contextos son muy desiguales, ya que unas proceden de excavaciones recientes, y otras son referencias "orales» recogidas por eruditos. Así Arquiña (8) de Vilaseco (Vimianzo, La Coruña), «megalito bajo túmulo" donde se recogió un hacha plana (Montegudo, 1977: n. ${ }^{\circ}$ 296A); Mámoa de Boel (Outes, La Coruña), «dolmen tumular» en cuya cámara fueron localizados dos puñales, junto a un «esqueleto de un guerrero" (?) (Murguía, 1888: 55); Mámoa de Monte Penamá (Allariz, Orense) «con cámara no determinada, de la cual conservaba algunas piedras» en cuyo interior apareció un puñal (Cuevillas, 1955: 11); Anta de Penacoba (Melide, La Coruña) de la que procedería una «espada de bronce» (Álvarez, 1907); y Túmulo dolménico de Lobán (Vilalba, Lugo), explorado por Ángel del Castillo en 1916, a quien los paisanos habían referido que albergaba piedras de cámara y donde se localizó un hacha plana (Pérez Bustamante et alii, 1924: 23). En el Túmulo 213 de Porto Roibo (As Pontes, La Coruña) Maciñeira (1943: 15-16) puso al descubierto $50 \mathrm{~cm}$ de la extremidad de un gran soporte. Según su propia descripción, era entonces uno de los mayores de la comarca ortegalesa, con un diámetro de 29 metros. A su pie se localizó una «cuña de cobre».

Desconocemos cualquier otro aspecto de estos contextos, considerando toda la prudencia

(8) En la toponimia gallega «Arquiña» es una cámara ortostática. "Mámoa», sin embargo, sólo es en principio un túmulo. 


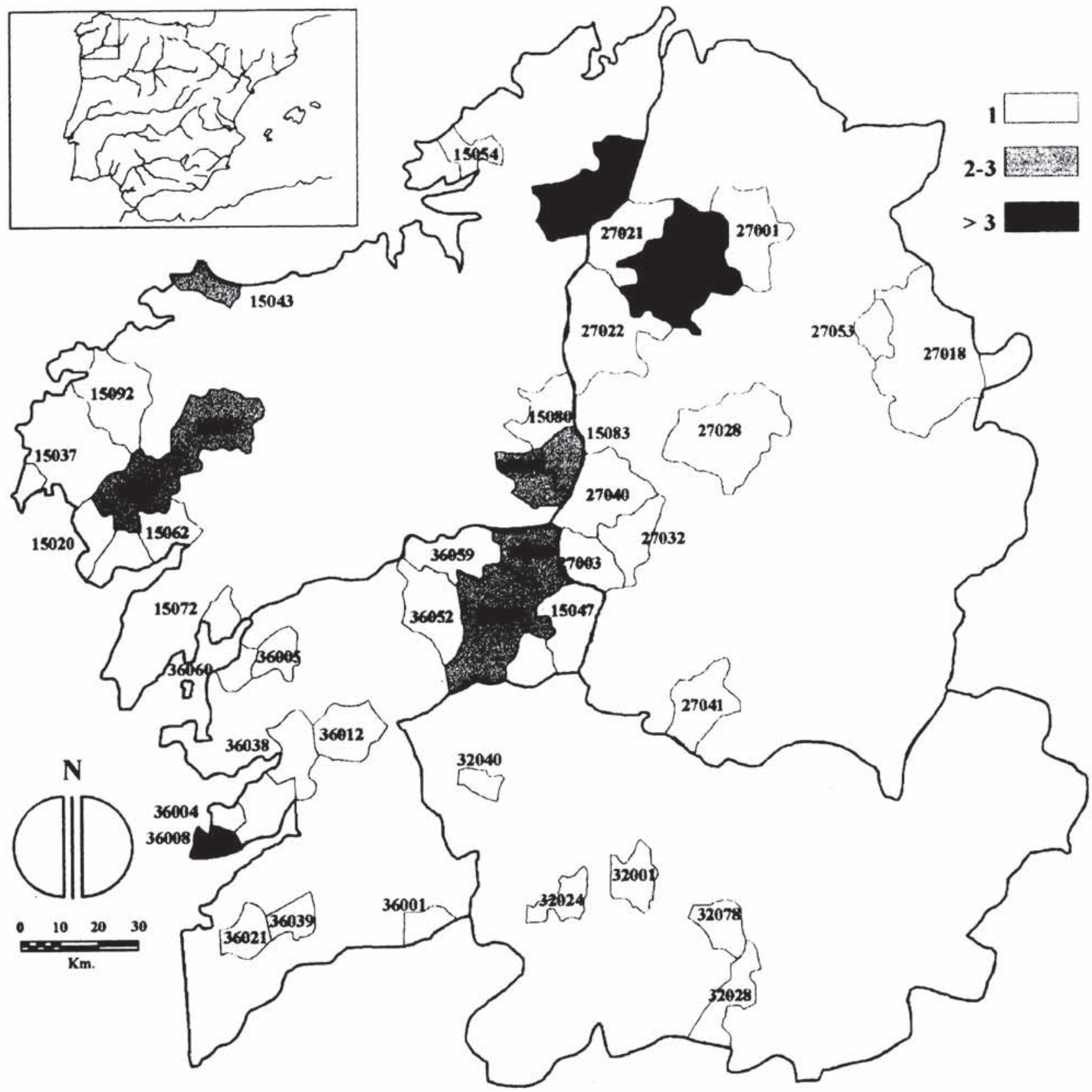

Fig. 1. Distribución de los puntos arqueológicos (PAs) con metal en Galicia. La trama expresa la densidad por municipios. A continuación se expresan los códigos municipales y la relación de PAs con su nombre genérico. No se incluyen los gallegos pero de local desconocido.

\section{LA CORUÑA:}

\section{GA15020- Carnota}

GA15037- Fisterra

GA15043- Malpica de Bergantiños

\section{GA15045- Mazaricos}

GA15046- Melide
Cista de Carnota, Pedra Marrada

Cercanías Playa Langosteira

Cambre, Aviño

Castro Nemenzo, Leoilo

Cista de Taraio, Cerqueda

Túmulos con cámara 4 y 2 de Parxubeira, San Fiz de Eirón

Túmulo con cámara de Campo Grande

Castro de Donide, Maceda

Nogueira

Pena Grande, Oleiros

Túmulo con cámara de Penacoba 
(iAl5054- Naron

GAlFik2. Outes

(iA15070). As Pontes

(iA 15072- Rianxo

(iA 15077. Santa Comba

GA15078- Santiago de (ompostela

GA15083- Toques

GA15092. Vimianzo

ORENSE:

GA.32001- Allariz

GA32024- Celanova

GA32()28-Cualedro

GA.32()40)- Leiro

GA32078-Sarreaus

\section{LUGO:}

GA27001 - Abadín

GA27003- Antas de Ulla

GA27018- A Fonsagrada

GA27021- Xermade

GA27022- Guitiriz

GA27028- Lugo

GA27032- Monterroso

GA27040- Palas de Rei

GA27041- Pantón

GA27053- Ribeira de Piquín

GA27065- Vilalba

\section{PONTEVEDRA:}

GA36001- Arbo

GA36004- Bueu

GA36005- Caldas de Reis

GA36008- Cangas

GA36012- Cotobade

GA36020- Agolada

GA36021- Gondomar

GA36024- Lalín

GA36038- Pontevedra

GA36039- Porriño

GA36047- Rodeiro

GA36052- Silleda

GA36059- Vila de Cruces

GA36060- Vilagarcía de Arosa

GA36061- Vilanova de Arosa
Narion

Túmulo con camara de Boel

Túmulo con cámara de Porto Roibo

Túmulo sin cámara de Veiga dos Mouros. Vilavella

3 Túmulos sin cámara de Vilavella

Monte Lioira. Revolada da Cana. Leiro

Cista de Santa Comba

Santiago o Portomouro

Monte das Penas

Monte dos Mouros

Túmulo con cámara de Vilaseco. Castrelo

Túmulo de Monte Penama. Crimelas

Aguis

Cista de Chedeiro. A Pedrosa

Pena Corneira. Lamas

Roufeiro. Nocelo da Pena

\section{Gontán}

Islote del rio Ulla

Túmulo sin cámara de Chao de Cotara. Montes de Vilamaior

Túmulo de Roupar. Lousada

Castro de San Pedro de Buriz

Castro de Penarrubia, Orbazai

Monterroso

San Mamed do Carballal

A Bastida, Mañente

San Xurxo de Piquín

Samarugo

Alrededores del túmulo de Lobán, Samarugo

Túmulo con cámara de Lobán, Samarugo

Castro de Sta. $\mathrm{M}^{\mathrm{a}}$ de Carballido

¿Arbo?

Cela

As Silgadas.

O Fixón y O Fixón-Costa da Seixeira, San Andrés de Hío

Lavapés, San Andrés de Hío

Cista de Gandón, Aldán

Mesa de Montes

San Xurxo de Sacos

Ferreiroa

Túmulo de Agolada, San Pedro de Ferreiroa

¿Gondomar?

Cristimil

Túmulo de Monte das Cabras

Mourente

"Lerez".

Cista de Atios, Santa Eulalia de Tunes

Cista de As Antas, San Estebo de Carboentes

O Castañal, San Miguel da Ponte

Túmulo de Oirós, O Marco do Camballón

Marxión

Guidoiro Areoso que merece su inclusión en un estudio de conjunto.

La memoria de la necrópolis de Oirós (Vila de Cruces, Pontevedra), excavada en 1976 por Sierra Rodríguez, no ha sido publicada. Según las referencias de que disponemos (Ruiz-Gálvez, 1984: 436) en el terreno tumular de un monumento que cobijaba una pequeña cámara poligonal con corredor corto, se localizaron dos chapitas de oro.

Las únicas piezas recogidas sistemáticamente proceden de las excavaciones dirigidas por Rodríguez Casal (1989) en dos monumentos con cámara de la necrópolis de Parxubeira (San Fins de Eirón, La Coruña). El «Monumento 2»(A Mina de Parxubeira) presentaba una estructura

T. P., 52, n. ${ }^{\circ} 2,1995$

(c) Consejo Superior de Investigaciones Científicas 


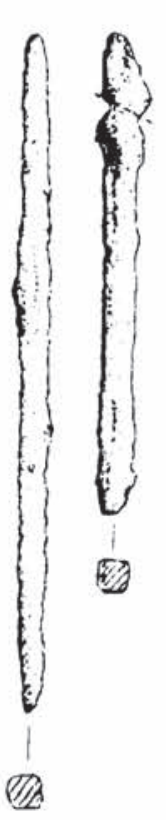

1
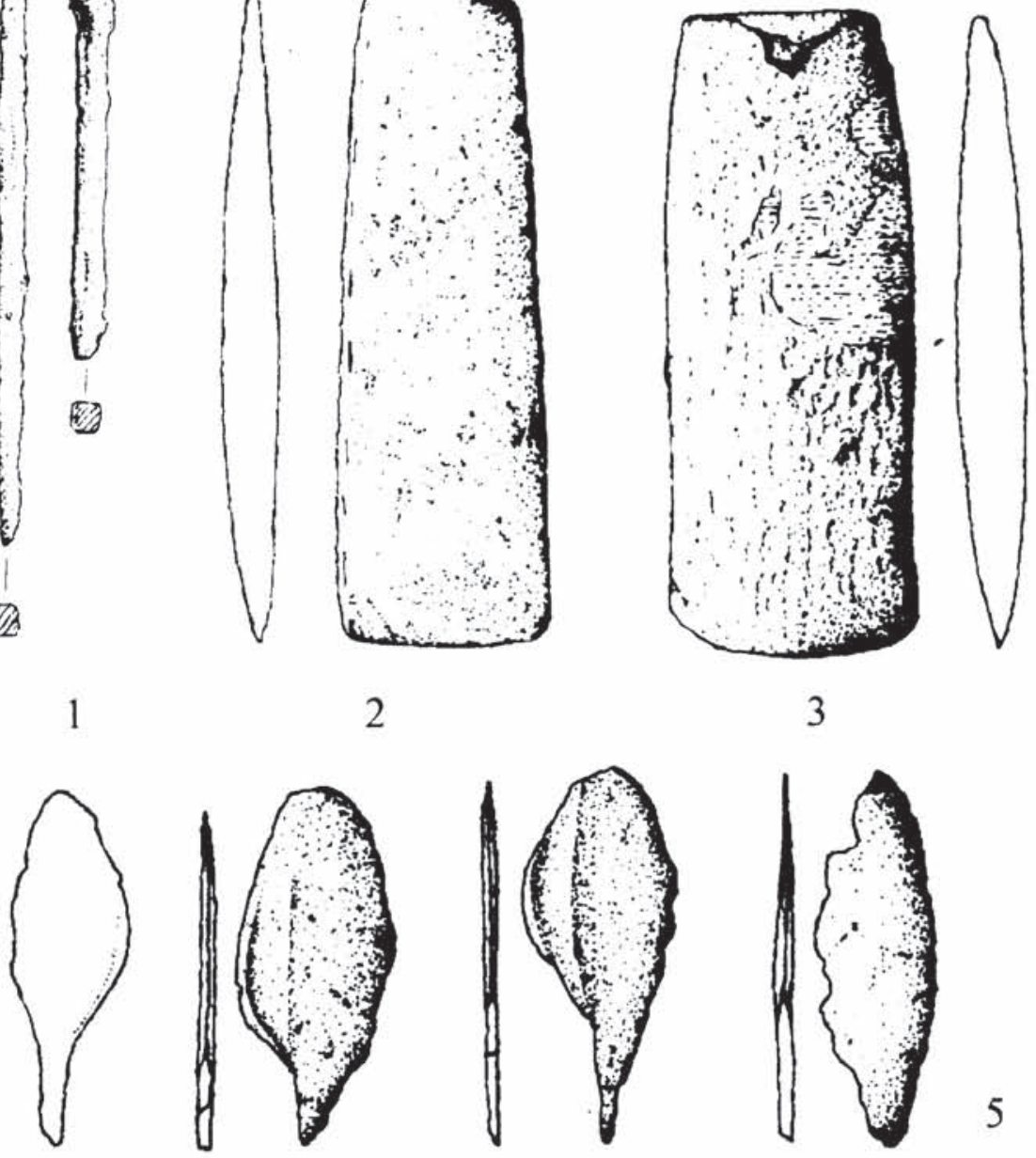

2
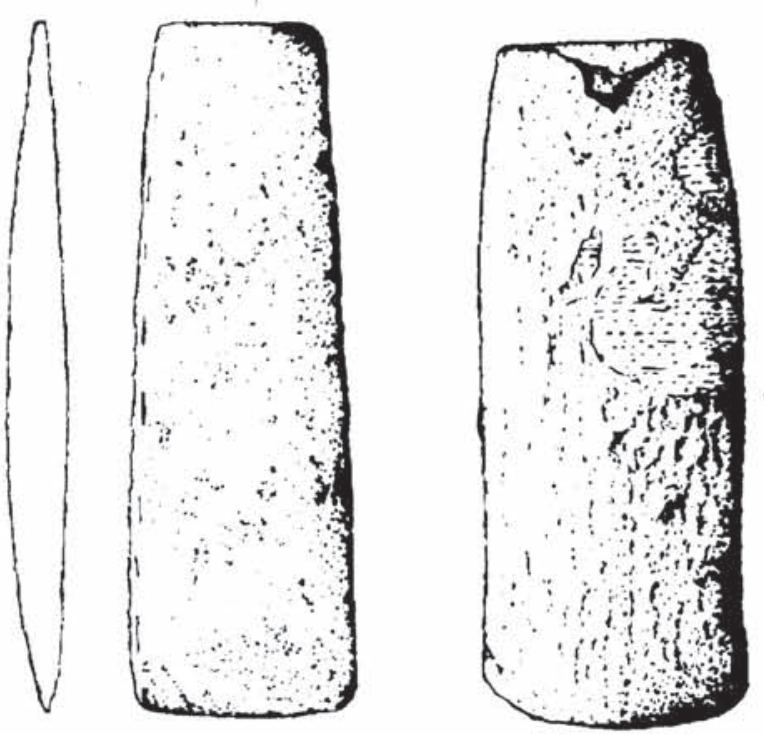

3

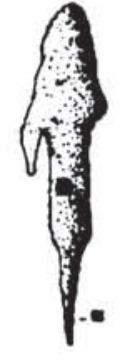

6

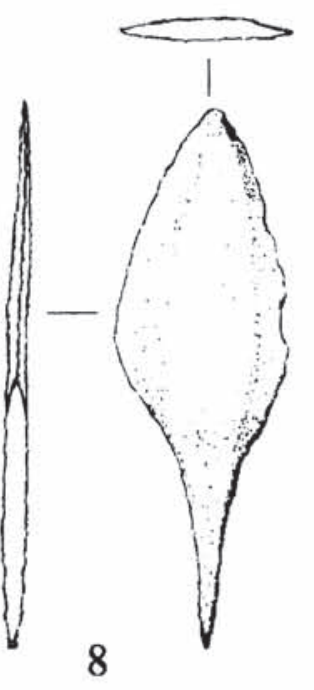

0

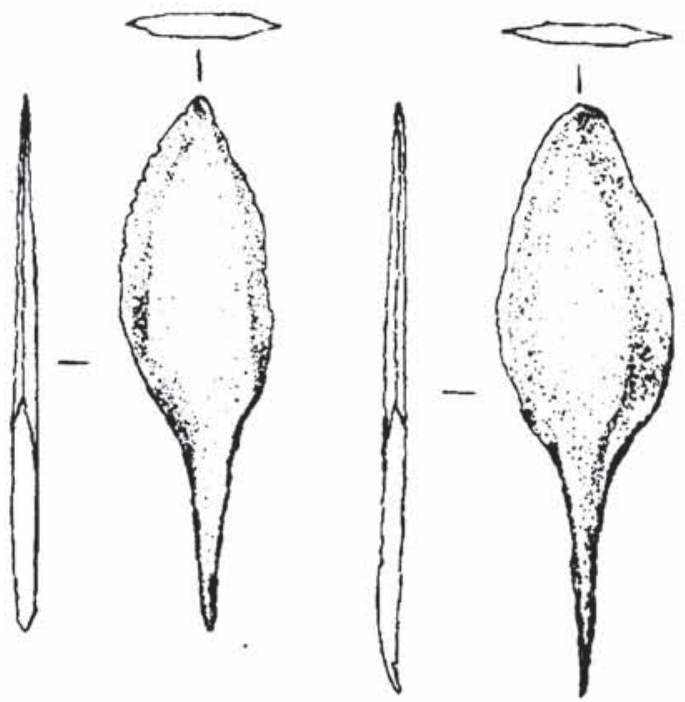

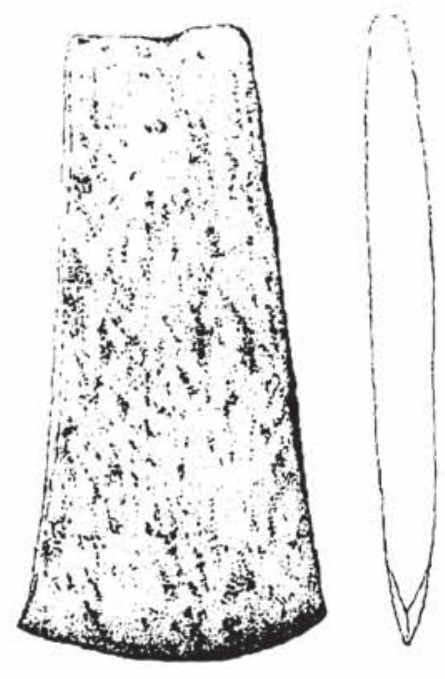

4

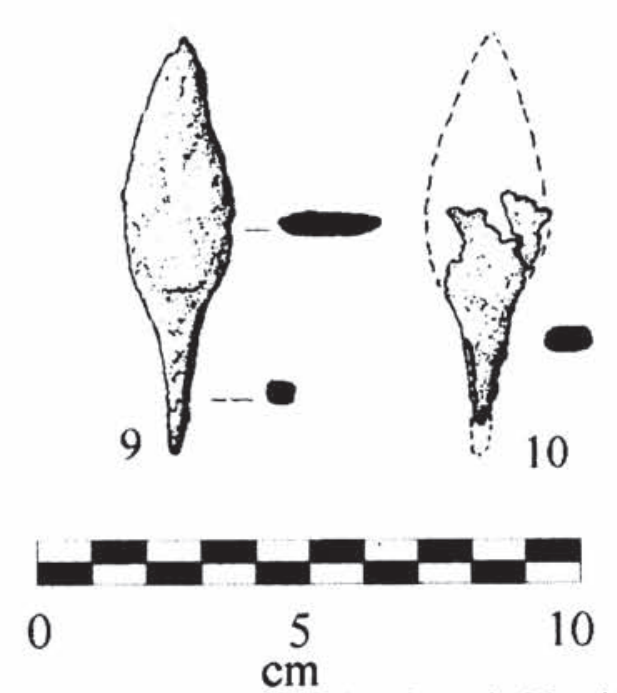

Fig. 2. 1. Punzones del yacimiento de Guidoiro Areoso (Vilanova de Arosa, Pontevedra); 2. Hacha plana de Marxión (Vilagarcía de Arosa. Pontevedra); 3. Hacha plana de A Cótara (A Fonsagrada, Lugo); 4. Hacha plana de Cristimil (Lalín, Pontevedra) (según Peña Santos, inédito); 5. Puntas tipo «Palmela» del túmulo 240 de Veiga dos Mouros (As Pontes, La Coruña); 6. Punta de flecha del depósito de Roufeiro (Sarreaus, Orense); 7. Punta de flecha de la provincia de Orense (?); 8. Puntas tipo «Palmela» de Monte das Cabras (Lalín, Pontevedra); 9-10. Punta tipo «Palmela» del monumento 4 de Parxubeira (Mazaricos, La Coruña) y fragmento de punta tipo «Palmela» del monumento 2 de Parxubeira (según Rodríguez Casal, 1989).

T. P., 52, n. ${ }^{\circ} 2,1995$ 

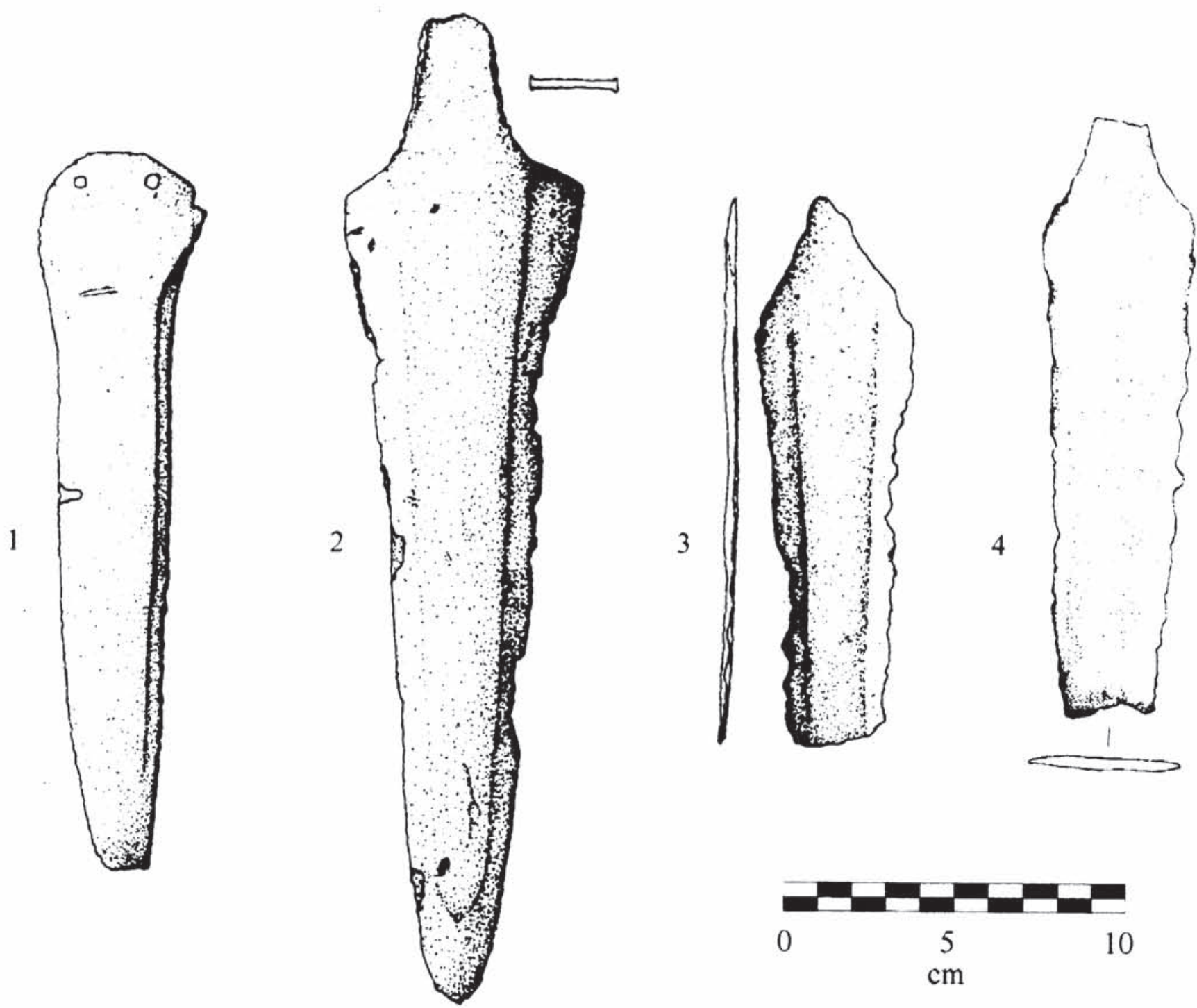

Fig. 3. 1-2. Puñal de remaches y puñal de lengüeta del depósito de Roufeiro (Sarreaus, Orense); 3 . Puñal de lengüeta de Veiga dos Mouros (As Pontes, La Coruña); 4. Puñal de lengủeta de Monte das Cabras (Lalín, Pontevedra).

de acceso («atrio») en donde fueron exhumados diversos artefactos, como estelas y betilos. Dentro de la cámara, poligonal y con corredor corto, apareció un fragmento de punta tipo «Palmela». $\mathrm{El}$ «Monumento 4» albergaba en su zona central un anta de forma general subcircular, sin corredor (definida así por los calzos), cuya entrada estaba tapiada por un relleno irregular de piedras. Una punta tipo "Palmela» fue hallada sobre la coraza que cubría el túmulo.

- Túmulos sin cámara: Tres túmulos distintos de Vilavella (As Pontes, La Coruña), todos pequeños y sin piedras, proporcionaron: un hacha plana, una punta tipo «Palmela» y fragmentos de otras respectivamente (Cuevillas, 1955: 8). Respecto al túmulo 240 de Veiga dos
Mouros, también en Vilavella, al parecer no alcanzaba el metro de altura, pero no está claro si estaba formado exclusivamente de tierra (Cuevillas, 1955) o si lo recubría una capa o coraza de pequeños pedruscos (Maciñeira, 1941: 365). Sobre la composición del ajuar tampoco hay acuerdo, puesto que el primero alude a una diadema, un puñal y cuatro puntas tipo «Palmela», y el segundo añade una punta más. El conjunto de Monte das Cabras (Lalín, Pontevedra) procede al parecer, de un túmulo sencillo (García, 1980: 29), y el hacha plana de A Cótara (A Fonsagrada, Lugo) de una mámoa que no presentaba cámara (López Fernández, 1992).

- Túmulos indefinidos: Álvarez Carballido (1907) refiere que en Campo Grande (Melide, 

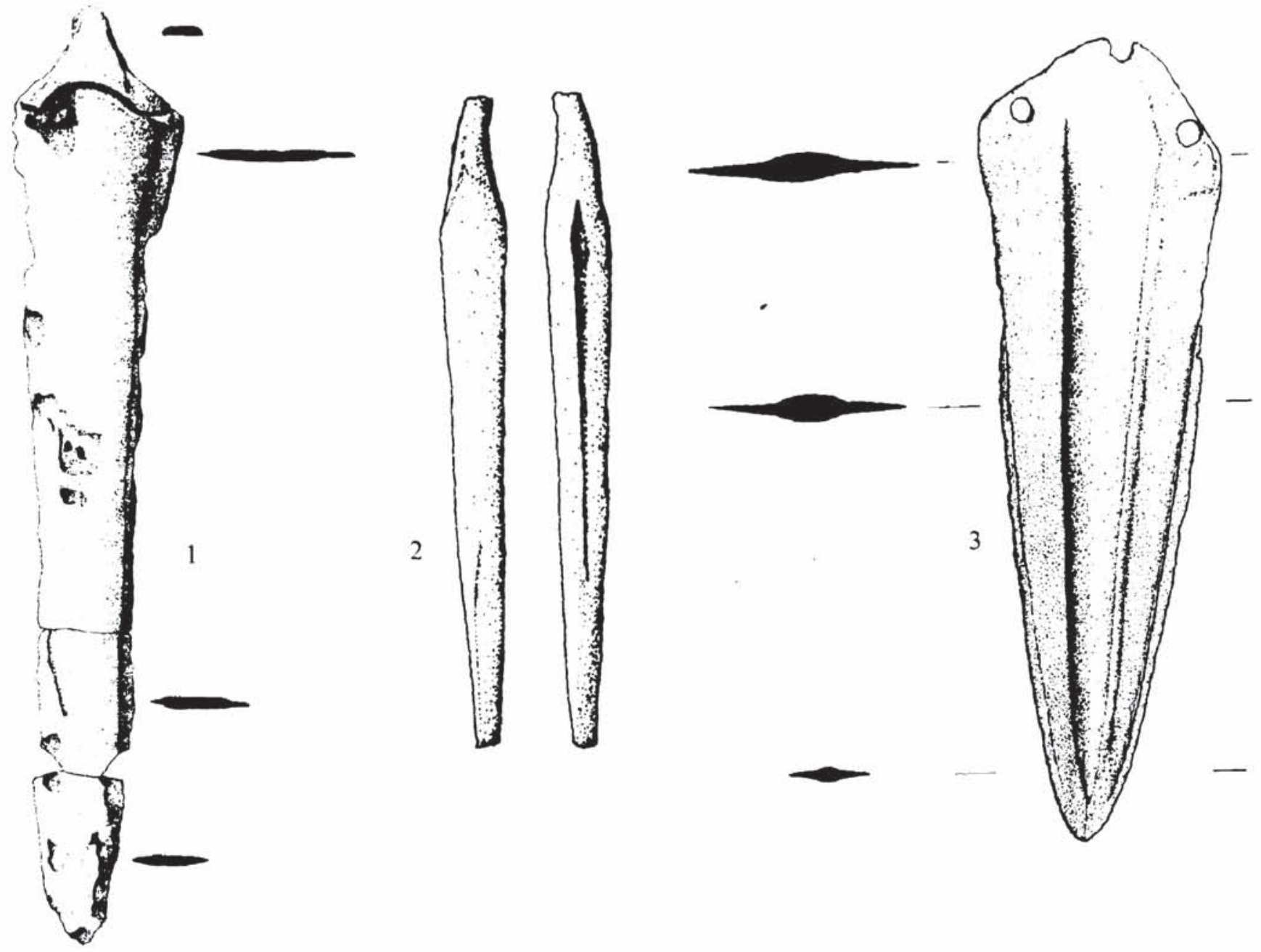

Fig. 4. Punal-espada de Santa Comba (La Coruña) $(360$ x 62 mm.) (según Ruiz-Gálvez, 1979); 2. Elemento para la producción de puñales de Roufeiro (Sarreaus, Orense) (147.5 x $14 \mathrm{~mm}$.); 3. Alabarda de Leiro (Rianxo, La Coruña) (258 x 75 mm.) (según Meijide, 1989).

La Coruña) apareció una lanza de cobre al deshacerse un túmulo. Otros dos conjuntos arqueológicos de gran importancia, ambos constituidos por piezas de oro, como son Cícere (Santa Comba, La Coruña) y Agolada (Pontevedra), tampoco detallan las circunstancias del hallazgo. Según Monteagudo (1953: 292-293) el primero procede de un túmulo. El segundo fue un hallazgo casual producido hacia 1920 al realizarse las obras de la carretera entre Lalín y Agolada, aunque otra versión refiere que procede de un túmulo de la necrópolis del Campo do Xastre (Filgueira y García Alén, 1978: 91).

- Fosa bajo túmulo: No incluimos el Túmulo de Roupar (Xermade, Lugo) dentro del grupo de túmulos con cámara por parecernos que su mayor complejidad merece un tratamiento aparte. En el piso del túmulo, dos piedras paralelas delimitaban un pequeño agujero con material campaniforme. El metal (una espiral de cobre y fragmentos amorfos) apareció «en diversos puntos de la zona excavada». La publicación de este yacimiento, no aclara si la «fosa" se trata de una intrusión, o es sincrónica con el resto de los materiales (Criado et alii, 1981: 455).

\subsubsection{Cajas de piedra bajo tierra}

En Galicia han aparecido objetos metálicos en siete cistas: Carnota, Taraio (Malpica) y Santa Comba en La Coruña; Chedeiro (Cualedro) en Orense; As Antas (Rodeiro), Gandón 2 
(Cangas) y Atios (Porriño) en Pontevedra (9). Las estructuras de Chedeiro y As Antas aparecieron al roturar campos de cultivo, y Atios. Carnota y Taraio casualmente en terrenos llanos (Gandón 2: $185 \times 60 \times 35 \mathrm{~cm}$.: Carnota: $106 \times 70$ x $70 \mathrm{~cm}$.; Atios $150 \times 30$ × $60 \mathrm{~cm}$.; As Antas y Taraio $140 \times 100 \mathrm{~cm}$. y $70 \times 70 \mathrm{~cm}$. la losa de cierre respectivamente).

\begin{tabular}{||l|c|c|}
\hline CONTEXTO & PAs & Objetos \\
\hline Desconocido & 34 & 38 \\
\hline Túmulo con cámara & 8 & 10 \\
\hline Túmulo sin cámara & 6 & 14 \\
\hline Túmulo indefinido & 3 & 9 \\
\hline Fosa bajo túmulo & 1 & 2 \\
\hline Cista sin túmulo & 7 & 12 \\
\hline Funerario indefinido & 2 & 2 \\
\hline Castro o cercanías & 7 & 7 \\
\hline Habitacional & 4 & 6 \\
\hline Depósito & 2 & 49 \\
\hline No definido & 8 & 14 \\
\hline TOTAL & 82 & 163 \\
\hline
\end{tabular}

Tabla 2. Distribución del número de puntos arqueológicos (PAs) con metal y del de los correspondientes objetos por contextos.

En Carnota y Gandón 2 se localizó un brazal de arquero asociado con un puñal de lengüeta y una posible punta tipo «Palmela» respectivamente. En Taraio y As Antas, el puñal de lengüeta se relaciona con vasos cerámicos lisos subcilíndricos (10). De Santa Comba procede un

(9) Para la bibliografía sobre las cistas, así como los asentamientos, remitimos a Ruiz-Gálvez (1984) o Comendador Rey (1991-92).

(10) También denominados tipo "florero" o cerámica "Tipo Taraio", se trata de vasos de pequeño tamaño con una morfología genérica de tipo subcilíndrico, fondo plano y con la boca suavemente abierta. Como se ha puesto de manifiesto (Suárez, 1993), la sencillez de la forma no permite una caracterización específica, por resultar demasiado genérica. puñal-espada sin más referencias. En Atios, dos puñales, uno largo y otro corto, aparecieron junto a dos cilindros de oro y dos espirales de plata, además de un bloque de cuarzo.

\begin{tabular}{||l|c|c||}
\hline CONTEXTO & PAs \% & O \% \\
\hline Desconocido & 41,45 & 23,4 \\
\hline Funerario & 33 & 30,05 \\
\hline Castro o cercanías & 8,53 & 4,30 \\
\hline Habitacional & 4,87 & 3,70 \\
\hline Depósito & 2,4 & 30,05 \\
\hline No definido & 9,75 & 8,5 \\
\hline
\end{tabular}

Tabla 3. Distribución del porcentaje de puntos arqueológicos (PAs) con metal y del de los correspondientes objetos $(\mathrm{O})$ por contextos.

En tres de ellas se recogieron precarios restos de inhumaciones que no han sido estudiados o se han perdido (Carnota, Chedeiro, Taraio). Gandón 1, cista de pequeñas dimensiones vecina de Gandón 2, albergaba una cremación (Peña Santos y Rey, 1993: 30).

Arquitectónicamente algunas cistas mantienen rasgos «megalíticos», como Gandón 1 que apareció rodeada de un tosco cinturón lítico, o Carnota y Chedeiro, cuyas lajas estaban calzadas por cantos.

En ocasiones se presentan en conjuntos (¿necrópolis?), donde no todas contienen ajuares metálicos (Gandón, Chedeiro, Carnota). En el caso de Chedeiro, una de las cistas proporcionó una espiral de plata, mientras otras vasos cerámicos troncocónicos, estos últimos de amplia presencia y perduración en el Norte de Portugal (Bettencourt, 1995: 111).

\subsection{Contextos habitacionales}

Es bastante frecuente la consideración como procedentes de castros de algunas piezas metálicas aisladas, aunque para ninguna se especifica su localización concreta. Su vinculación con los castros, aparte de por su proximidad física, debe entenderse dentro de las construcciones teóricas de una determinada fase de la investigación, aunque posiblemente proceden de ocupaciones 


\begin{tabular}{|c|c|c|c|c|c|c|c|c|c|c|}
\hline \multirow[b]{2}{*}{ CONTEXTO } & \multicolumn{2}{|c|}{ Gil } & \multicolumn{2}{|c|}{$\mathrm{G} 2$} & \multicolumn{2}{|c|}{ G.3 } & \multicolumn{2}{|c|}{ G4 } & \multicolumn{2}{|c|}{ G.5 } \\
\hline & PA & $\mathrm{O}$ & PA & $\mathrm{O}$ & PA & $\mathrm{O}$ & PA & $\mathrm{O}$ & PA & $\mathrm{O}$ \\
\hline Desconocido & - & - & 31 & 33 & 1 & 1 & 1 & 3 & - & - \\
\hline No definido & 1 & 2 & 5 & 9 & 1 & 1 & 1 & 1 & 1 & 1 \\
\hline Túmulo sin cámara & - & - & 6 & 13 & - & - & 1 & 1 & - & - \\
\hline Túmulo con cámara & - & - & 6 & 7 & 1 & 1 & 1 & 2 & - & - \\
\hline Túmulo indefinido & - & - & - & - & 1 & 1 & 2 & 8 & - & - \\
\hline Fosa bajo túmulo & - & - & - & - & - & - & 1 & 1 & - & - \\
\hline Cista sin túmulo & - & - & 4 & 5 & 1 & 1 & 2 & 5 & - & - \\
\hline Funerario indefinido & - & - & 1 & 1 & - & - & - & - & - & - \\
\hline Habitacional & - & - & 1 & 1 & - & - & - & - & 3 & 4 \\
\hline Castro o cercanías & - & - & 6 & 6 & 1 & 1 & - & - & - & - \\
\hline Depósito & - & - & 1 & 12 & - & - & 1 & 36 & 1 & 1 \\
\hline
\end{tabular}

Tabla 4. Distribución del número de puntos arqueológicos (PA) con metal y del de los correspondientes objetos (O) por contextos y grupos morfofuncionales.

\begin{tabular}{|c|c|c|c|c|c|c|c|c|c|c|c|}
\hline CONTEXTO & $\mathrm{H}$ & PL & PR & PP & PF & ES & A & JT & DI & SP & $\mathrm{C}$ \\
\hline Desconocido & 18 & 3 & - & 10 & 1 & 1 & - & 2 & - & - & - \\
\hline No definido & 1 & 6 & - & 2 & - & - & 1 & - & - & - & - \\
\hline Túmulo sin cámara & 2 & 2 & - & 9 & - & - & - & - & 1 & - & - \\
\hline Túmulo con cámara & 2 & 2 & 1 & 2 & - & $1 ?$ & - & - & - & - & - \\
\hline Túmulo indefinido & - & - & - & - & - & - & - & 3 & 1 & - & - \\
\hline Fosa bajo túmulo & - & - & - & - & - & - & - & - & - & 1 & - \\
\hline Cista sin túmulo & - & 5 & - & $1 ?$ & - & 1 & - & - & - & 3 & - \\
\hline Funerario indefinido & 1 & - & - & - & - & - & - & - & - & - & - \\
\hline Habitacional & - & - & 1 & - & - & - & - & - & - & - & 3 \\
\hline Castro o cercanías & 5 & 1 & - & - & - & - & - & - & - & - & - \\
\hline Depósito & 2 & 1 & 8 & - & 1 & - & $2 ?$ & - & - & - & - \\
\hline TOTAL & 31 & 20 & 10 & 24 & 2 & 3 & 3 & 5 & 2 & 4 & 3 \\
\hline
\end{tabular}

Tabla 5. Distribución del número de piezas de las diferentes clases morfológicas por contextos: Grupo 2: H Hacha plana; PL Puñal de lengüeta; PR Puñal de remaches; PP Punta tipo «Palmela»; PF Punta de flecha con tope. Grupo 3: ES Puñal espada; A Alabarda. Grupo 4: JT Joya de tiras; DI Diadema; SP Espiral. Grupo 5: C Crisol. 
previas o asentamientos de localización cercana. tanto domésticos como funerarios.

La aparición de objetos metálicos acabados en los núcleos habitacionales más antiguos es casi nula. Sólo dos yacimientos localizados en la Península del Morrazo (Pontevedra) testimonian la práctica de la actividad metalúrgica.

Del nivel reciente de Lavapés (Hío, Cangas, Pontevedra) proceden dos fragmentos de barro con escorias en su interior. Este nivel arqueológico proporcionó vasos globulares de pequeño y medio tamaño con decoración inciso metopada del tipo Penha, cerámica impresa, industria lítica de lascas de pizarra y cuarzo, así como abundantes cotiledones carbonizados de bellotas, que han servido para datar por $\mathrm{C} 14 \mathrm{el}$ nivel reciente: Gak-11188: $3930 \pm 120$ a.p., $1980 \pm 120$ a.C. Los análisis palinológicos y edafológicos indicaron la presencia de cereal.

En el nivel reciente del yacimiento de $\mathrm{O}$ Fixón (Hío, Cangas, Pontevedra) un fragmento de crisol se localizó en relación directa con una concentración de carbones. Otros materiales significativos son: cerámica campaniforme, mayoritariamente de estilo internacional pero también con decoración incisa e impresa; industria lítica de lascas de cristal de roca, pulidores, manos de molino; fragmentos amorfos de hematites. A este nivel se asocia una datación GaK12317: $3830 \pm 130$ a.p., $1880 \pm 130$ a.C., a partir de carbones procedentes de las tierras que conformaban un cambio de coloración en el suelo natural, delimitado por tres pequeños agujeros de poste. Los análisis palinológicos no detectaron polen de cereal ni de las plantas que generalmente lo acompañan.

A unos 200 m. de O Fixón, se sitúa otra concentración de materiales que Suárez (1993) denomina O Fixón-Costa da Seixeira y que considera de ergología postcampaniforme. Además de un alfiler de cabeza enrollada de problemática contextualización, se localizó un resto de fundición con aleación $\mathrm{Cu} / \mathrm{Sn}$ (11).

Cercano a los anteriores se sitúa el yacimiento de Mesa de Montes que, a diferencia de aquéllos situados a poca distancia de la línea de playa, está enclavado en una pequeña meseta de un

(11) Análisis realizado en el Instituto de Cerámica de la Universidad de Santiago, por el Dr. Francisco Guitián Ojea en 1993. Se destruyó la muestra, por lo que lamentablemente sus resultados no son contrastables con los del Proyecto de Arqueometalurgia. cordal montañoso. En uno de los cortafuegos de la pendiente apareció un pequeño puñal de remaches. Es muy probable la relación de la pieza con este asentamiento, aunque desconocemos si hay una o varias ocupaciones con las que pudiera relacionarse (12).

\subsection{Piezas ocultas: «depósitos»}

Como un conjunto de materiales retirados intencionalmente de la circulación mediante su ocultación, recogemos dos hallazgos: Roufeiro (Nocelo da Pena, Sarreaus, Orense) y Caldas de Reis (Pontevedra).

En Roufeiro (López Cuevillas, 1955: 12) las piezas se localizaron casualmente dentro de una vasija de barro que se perdió. El conjunto asocia elementos diversos: dos hachas planas de tipologías distintas, seis puñales de remaches, dos piezas que podrían ser consideradas alabardas atípicas o puñales alabardados, un puñal de lengüeta, y una punta de flecha de base pedunculada con tope y aleta. Además se recogió un objeto considerado corrientemente como «perforador", cuyo reciente examen ha permitido plantear la hipótesis de que se trate de una forma previa de producción de puñales por forja, hecho que apoya su peso, similar al de los del mismo depósito (13). Respecto al Conjunto de Caldas, compuesto en la actualidad por 36 objetos de oro, no apareció en el interior de una vasija trípode, como es creencia extendida (RuizGálvez, 1978), sino agrupado directamente sobre el substrato de roca disgregada (14). Repartidos en dos aros grandes, se insertaban diversos lingotes-aro (denominados generalmente brazaletes), en medio de los cuales se disponían tres recipientes, uno con un peine en su interior, y todo cubierto por una diadema de lámina que fue troceada y de la que sólo quedan fragmentos.

(12) Este yacimiento ofrece en superficie cerámicas del tipo Penha. Sin embargo, podrían existir indicios de la existencia de un asentamiento posterior, según comunicación personal de José Suárez Otero, a quien queremos agradecer su amabilidad tanto por permitirnos el estudio de ésta y otras piezas, como por toda la información al respecto que nos proporcionó.

(13) Agradecemos la sugerencia de esta hipótesis a Bárbara Armbruster (Universidad de Tübingen), con quien compartimos gran parte de nuestra tarea de catalogación.

(14) Informaciones contrastadas con las del propio descubridor, D. Amalio Touceda. 


\subsection{Contextos no definidos}

En el islote de Guidoiro Areoso (Vilanova de Arosa, Pontevedra), situado en la Ría de Arosa, se localizó un complejo yacimiento de difícil definición del que se conocen, al menos, tres estructuras, dos de ellas de carácter funerario. La estructura II, de tipología singular y funcionalidad no definida, apareció al ampliar el sondeo de un «concheiro» con restos claros de actividad antrópica. Sellada por una formación dunar, no manifestaba indicios de su existencia en superficie. Se compone de una anillo pétreo exterior de un metro de ancho, en cuyo interior, en disposición casi concéntrica y por debajo del nivel de base del anillo externo, aparece otro formado por una veintena de losas imbricadas.

En una primera intervención realizada en este yacimiento se había documentado una estratigrafía muy simple: un paleosuelo cubierto por arena, atravesado en su parte media por un "concheiro" en el que se localizaron materiales idénticos a los del interior de la estructura II, a la que se adosa (sin pasar por debajo ni por enci$\mathrm{ma})$, por lo que se puede deducir que era o bien sincrónica, o bien posterior a esta estructura, pero nunca anterior. De una muestra obtenida del «concheiro» es la datación GrN-16.108: $4020 \pm 40$ a.p., $2070 \pm 40$ a.C. La cerámica es el material más representado, respondiendo en términos generales al tipo Penha. Asimismo, en prospección superficial se había documentado campaniforme de estilo internacional en su variedad lineal. En el interior de la estructura II apareció un punzón en una zona intacta.

En la siguiente intervención se complicó esta estratigrafía al asomar otra acumulación de piedras alineadas situadas por encima del «concheiro», y por tanto posiblemente posterior a él, aunque carecemos de referentes para cuantificar el intervalo. En relación con ella se localizó un segundo punzón, junto a otra serie de materiales que podrían apuntar cierta modernidad: perfiles cerámicos evolucionados, fondos planos, decoración plástica, cerámica campaniforme. Están siempre por encima de la cota de nivel de base de la cerámica inciso metopada tipo Penha que se articula con el «concheiro» (Rey García, 1991).

De momento no es posible precisar más sobre la contextualización concreta de estos materiales dentro del yacimiento, dado que es necesaria una nueva intervención para definir su estratigrafía.
Un conjunto al que podría atribuirse el carácter de depósito (Meijide Cameselle, 1989: 151), es el recuperado en el Monte Lioira (Leiro, Rianxo). Más conocido como «Depósito de Leiro", agrupa cinco puñales de lengüeta y una alabarda. Sin embargo Meijide indica que las piezas se hallaron diseminadas y que existe la posibilidad de que procedan del arrasamiento de un campo de cistas.

Relacionadas con rocas o abrigos rocosos, han aparecido varias piezas: un hacha plana entre las grietas del petroglifo Lombo da Costa (Cotobade, Pontevedra); una punta tipo «Palmela" extraída por un niño de una concavidad en la Pena Grande de Oleiros (Toques, La Coruña), «donde pendía de un alhambre que se amarraba con dos anillos a dos clavos en una casiña labrada en la propia roca»; una (o dos) punta del mismo tipo localizada al pie de una piedra oscilante de amplia tradición oral en Samarugo (Vilalba, Lugo); otras dos recuperadas en Liméns (Cangas, Pontevedra) al dinamitar un peñasco; por último, durante una reciente prospección en el Monte das Penas (Melide, La Coruña), se recogió un puñal de lengüeta al pie de un abrigo rocoso (15). Aunque carecemos de información para determinarlo, podría existir algún tipo de intencionalidad o pauta en su deposición.

\section{METALURGIA Y CAMPANIFORME: ANÁLISIS DE LOS PLANTEAMIENTOS Y PLANTEAMIENTOS PARA SU ANÁLISIS}

El análisis de los presupuestos sobre la relación metalurgia-campaniforme en Galicia se articula según la siguiente secuencia:

- Un momento precampaniforme, en el que la metalurgia se introduce.

- Un momento campaniforme en el que aparecen nuevos tipos metálicos característicos y se desarrollan nuevas técnicas.

- Un tercer momento, con dos lecturas según los autores: para unos sucede al anterior un momento en que una «metalurgia de tradición campaniforme» aparece en los enterramientos ya disociada de la cerámica campanifor-

(15) Las referencias para estos hallazgos respectivamente son: Sobrino (1952: 199); López Cuevillas (1933: 53); Villaamil (1906-1907: 161); García Alén (1970: 39) y Criado et alii (1991: 178). 
me que es sustituida por otras formas propias del Bronce Antiguo. Para otros es un momento no necesariamente posterior al campaniforme (o solapándose con éste) cuya producción metálica continúa con las mismas características.

\subsection{Sobre la existencia de una producción meta- lúrgica precampaniforme en Galicia}

Algunos autores (Vázquez, 1992: 49; Blas Cortina, 1987: 66-67) defienden una producción metalúrgica previa a la introducción del campaniforme en base a: la presencia de objetos metálicos considerados de tecnología arcaica, como ciertas hachas planas; la continuidad megalitismo-metalurgia (López Cuevillas, 1955); la presencia de dos fragmentos de barro con escorias en su interior en el segundo nivel de ocupación del yacimiento de Lavapés (Peña Santos, 1984: 149-178).

Recientemente la cuestión de la actividad metalúrgica precampaniforme ha sido planteada también para la orfebrería "precastreña" (Almeida et alii, 1994).

Respecto a las hachas planas, tienen un porcentaje alto de descontextualización. Algunos de los ejemplares más toscos proceden de contextos tumulares, como el túmulo sin cámara de A Cótara (A Fonsagrada, Lugo) y el dolmen de Lobán (Vilalba, Lugo), sin embargo no tenemos noticia de su aparición en cistas (16). Tampoco se han encontrado en asociación con otros objetos excepto en el depósito de Roufeiro (17), ni figuran en las representaciones al aire libre. La aparición de un molde en los «alrededores» del dolmen Capela dos Mouros (Vilalba, Lugo) prueba la existencia de una producción local ya intuible por la homogeneidad del conjunto. Sin embargo, los datos tecnológicos son aún escasos. La falta de control del proceso puede apreciarse en contracturas o deformaciones. El acabado de algunas hachas es rudo, ya que presentan la estructura de bruto de fundición apenas regularizada. Tampoco se observa un especial cuidado en la configuración del filo.

La inclusión de estas piezas metálicas en túmulos justifica la hipótesis de la introducción de la metalurgia sobre tradiciones anteriores

(16) A excepción de la más que dudosa existencia de una necrópolis de cistas en Mourente, de donde procedería una (López Cuevillas, 1925: 101; Álvarez Limeses, 1936: 52).

(17) Recientemente en Fragão da Pitorca (Chaves), en el Norte de Portugal, se localizaron asociadas con cerámica tipo Penha, un hacha plana y una espiral de oro (Inventario, 1993: 25). neolíticas, sin un impacto importante al menos sobre las funerarias. Más difícil es el establecimiento de este "impacto" para los asentamientos, debido a los escasos restos de actividad metalúrgica, así como a las dificultades de conexión con sus correspondientes enterramientos. El único testimonio de Lavapés aporta una información muy limitada. Sin embargo, es posible inferir del mismo yacimiento que la práctica de la metalurgia es una actividad esporádica y posiblemente experimental.

Sobre la vía de entrada de esta técnica, Vázquez (1992: 50) ha sugerido un origen meridional, vía litoral portugués y en relación con las culturas calcolíticas de la desembocadura del Tajo, basándose en la dispersión geográfica de ciertos tipos metálicos.

En cualquier caso, resulta más factible la hipótesis de la introducción inicial de objetos metálicos, y posteriormente la de su tecnología de fabricación, que la de un origen autóctono. En el mismo sentido apuntan los datos sobre los inicios de la producción de la metalurgia en el área asturiana y cántabra. A pesar de proponerse momentos anteriores al campaniforme en recientes publicaciones (Ontañón, 1994: 134151), los hallazgos son escasos y, en general, presentan particulares diferencias, especialmente los de la mitad oriental asturiana con respecto a los gallegos. Por ello es poco probable que los contactos con este área resultaran en la introducción de esta técnica en Galicia, aparte el obstáculo que constituye la orografía de las sierras orientales gallegas, con un número mínimo de hallazgos.

Resumiendo, consideramos que la hipótesis de la introducción de elementos metálicos y de la tecnología metalúrgica (en una o varias ocasiones) en un período previo a la aparición del «fenómeno campaniforme» es factible tal y como se ha planteado. Sin embargo, características tecnológicas como la falta de control sobre el proceso metalúrgico o la ausencia de acabados cuidados en las piezas pueden ser indicativas de esta primera producción, pero no son exclusivas de la misma.

\subsection{Sobre la existencia de una metalurgia «epi- campaniforme» 0 de «tradición campanifor- me» en Galicia}

Este problema se extiende al replanteamiento general de todo el «fenómeno campaniforme», tema muy amplio que se sale de los límites de este trabajo. 
El análisis de las distintas opiniones de los autores que han tratado este tema en pocos casos deja claro qué es lo que imprime su tradicional carácter a esta metalurgia: si la tecnología productiva o la morfología-tipología de los objetos y su asociación con elementos no cerámicos del ajuar campaniforme. Resulta complejo definir tal «tradición", cuando se carece de una buena caracterización de la metalurgia/as vincula$\mathrm{da} /$ as al fenómeno campaniforme en Galicia.

Desde un punto de vista tecnológico ya hemos visto cómo al menos de momento, no se puede hablar con propiedad de «metalurgia epicampaniforme o de tradición campaniforme».

Desde un enfoque morfo-tipológico-asociativo, en el registro arqueológico gallego aparecen objetos no cerámicos que se consideran de la particular panoplia campaniforme (Delibes y Fernández-Miranda, 1993: 50), siendo su contexto mayoritario de aparición, el funerario, especialmente de los grupos morfofuncionales 2Herramientas-Armas, 3-Armas, y 4-Adornos, ausentes de los asentamientos.

El tipo que más veces aparece relacionado con otros objetos (cerámicos, líticos, metálicos) es el puñal de lengüeta. Procede tanto de monumentos con túmulo como de cistas sin túmulo y es el más representado, junto a las alabardas, en los petroglifos. En cistas sin túmulo, los puñales se asocian con vasos subcilíndricos (denominados tipo «florero" o «Tarayo») de amplia diversidad morfológica, considerados característicos del Bronce Antiguo.

En túmulos sin cámara los puñales de lengüeta aparecen con varias puntas tipo «Palmela» (Monte.das Cabras, Veiga dos Mouros) tal y como observó Harrison (1974b: 85). No parece haber indicios de la presencia de cerámica, si bien se señala para el último, que monumentos similares contenían vasos campaniformes. Veiga dos Mouros integra cuatro puntas tipo «Palmela" de tipologías diversas. Esta particularidad, unida a la evidencia de su reutilización y a su distinta composición química, podría aludir a una reunión de materiales heterogéneos para un mismo ajuar, bien por intercambios, bien por otros medios, y no a una fabricación única y expresa para este fin (18). Por el contrario la tipo-

(18) Datos analíticos aún inéditos para Galicia del Proyecto de Arqueometalurgia (PB92-0315). Sin embargo, conviene ser prudentes al considerarlo como el ajuar original, debido a las diversas incidencias de la recuperación y conservación de este conjunto. logía de las puntas tipo «Palmela» de Monte das Cabras es igual para todas. Dado que por otro lado es la más común, habrá que esperar al estudio analítico de este conjunto para disponer de un elemento más de contrastación.

En la cista de Carnota el puñal se asocia a un brazal de arquero, tipo este último que también aparece en la cista de Gandón junto a un fragmento amorfo interpretado como punta tipo «Palmela» y fragmentos de cerámica lisa.

La distinta formación de los ajuares contradice, en cierto modo, la rigidez del concepto "Horizonte Montelavar». De su observación concluimos que la datación de algunos objetos metálicos «difíciles de disociar» del fenómeno campaniforme, en un momento posterior al de su «apogeo», se ha basado en la relación con formas cerámicas no campaniformes dentro de contextos funerarios tradicionalmente entendidos como del Bronce Antiguo: cistas. A su vez, estas ergologías cerámicas en conexión con el campaniforme en yacimientos domésticos, caracterizan esta etapa. Sin embargo, las «divergencias» en las producciones cerámicas nos siguen pareciendo un criterio insuficiente para la individualización de una etapa cultural respecto a la precedente, al menos mientras no se aclaren otros aspectos ergológicos y estructurales, como el cambio de ritual funerario. Por otra parte, son pocos los intentos de definir los contextos habitacionales del Bronce (19).

En general, todo este panorama nos aboca al problema de la indefinición del Bronce Antiguo en Galicia, o expresado de otra manera, a la ausencia de una «ruptura» en las tradiciones representadas por el registro arqueológico, hasta «la crisis» del segundo tercio del II milenio a.C., ya señalada por otros autores (Ruiz-Gálvez, 1987: 254; Peña Santos y Rey, 1993: 17). Esta problemática ha sido recientemente planteada también para el Norte de Portugal donde Bettencourt (1995: 111) sugiere que las alteraciones enunciadas para este período son fenómenos puntuales en un período en que algunas

(19) Es una excepción el reciente estudio de Méndez (1994: 85) sobre un conjunto de hábitats localizados en un valle interior de la Sierra de O Bocelo. Sin embargo entendemos que los considera pertenecientes al Bronce Inicial atendiendo a criterios cronotipológicos. Aporta varias dataciones que señalan una ocupación reiterada a lo largo del tiempo, definiendo los materiales de estas «áreas de acumulación» por sus cerámicas decoradas que inscribe «dentro de la tradición campaniforme o estilísticamente inscritas en la campaniformidad", sin grandes diferencias estilísticas entre unos PAs y otros. 
comunidades, en interacción con nuevos conocimientos, desenvuelven a distintos ritmos temporales un proceso de intensificación socio-económico que en varios aspectos parece perpetuar las tradiciones del Calcolítico Pleno.

\subsection{Sobre la existencia de una producción metá- lica durante el período de vigencia de la cerámica campaniforme}

A la vista de las síntesis y estudios, desde el 2400-2200 a.C. cuando se introducirían los primeros objetos metálicos, hasta el 1750-1500 a.C. (cronología del supuesto Horizonte Montelavar) la producción metálica adquiriría nuevas técnicas y formas que le imprimirían un «carácter campaniforme». Sin embargo, como hemos discutido, la ausencia de cerámica campaniforme en contextos funerarios donde sí hay piezas metálicas y la asociación de dichas piezas con cerămicas lisas lleva a un gran número de autores a incluir aquéllas en un momento posterior al apogeo del fenómeno campaniforme. Como resultado, y si observamos las propuestas cronológicas para piezas o conjuntos metálicos contextualizados, la producción que sería propia de la transición III-II milenio a.C. ha desaparecido.

Terminológicamente resulta paradójico que las piezas básicamente de cobre se incluyan en la Edad del Bronce. Otra cuestión que llama la atención es que, si bien se da como cierta la relación de ciertos objetos con el fenómeno campaniforme (como los brazales de arquero), sólo se acepta para los objetos metálicos cuando están en relación con el tipo cerámico característico. En Galicia se ha documentado en pocas ocasiones, pero sí la de objetos metálicos con brazales de arquero.

A modo de conclusión de esta parte, nuestra propuesta consiste en la necesidad de replantear tanto la cronología de esta producción metálica vinculada al Bronce Antiguo de acuerdo con la periodización tradicional, como su posible relación con otros fenómenos propios de la transición III-II milenio a.C. Esta propuesta incluye tener en cuenta los datos aportados por el estudio tecnológico. Al mismo tiempo, si se opta por mantener una terminología-estructura convencional Calcolítico/ Bronce Antiguo, es necesario definir en cada caso a qué nos referimos y con qué criterios, ya que consideramos que tal división en Galicia no se ajusta a la realidad ergológica, causando problemas de entendimiento entre los investigadores.

\section{NUEVOS ELEMENTOS, NUEVAS HIPÓTESIS}

Hemos pretendido señalar cómo se ha construido una periodización teórica en base a supuestas fases de producción metalúrgica sucesivas, que no son demostrables al menos de momento por una evidencia tecnológica, y difícilmente por evidencia arqueológica.

Un nuevo elemento de contrastación al que pronto podremos recurrir es el análisis tecnológico del conjunto de piezas incluidas en el Programa «Arqueometalurgia de la Península Ibérica: tecnología y cambio cultural durante la Edad del Bronce» (DGCYT PB92-0315), que ya ha comenzado a ofrecer algunos resultados. La analítica no va a solucionar los grandes problemas de la Prehistoria gallega que hemos planteado, sin embargo con la combinación de la información arqueológica y tecnológica (especial- mente las micrografías) esperamos obtener una mejor caracterización de las producciones metálicas, advertir sus diferencias o similitudes y trasladar nuevas preguntas al propio registro, comparando este modelo con el de otras áreas geográficas y culturales. Este procedimiento puede ser de utilidad para contrastar y/o rebatir algunas hipótesis relativas al tópico atraso cultural del Noroeste en la Prehistoria, entre otros en relación con la metalurgia (tópico tan recurrente como el del papel innovador del Argar en el Sureste).

En cuanto a la caracterización de la producción metálica, para aclarar si los cobres arsenicales son aleaciones fortuitas o intencionales y si son comunes a toda la producción metalúrgica o sólo a una parte de la misma, es necesario tanto el estudio de las piezas, como de los recursos minerales.

Respecto a la aleación Cu-Sn en el Noroeste, su aparición se viene atribuyendo al Bronce Medio con la presencia paulatina de aleaciones pobres de estaño en hachas de rebordes y del tipo Bujões-Barcelos (Ruiz-Gálvez, 1984: 360$361)$. Se ha considerado que la introducción de esta técnica fue consecuencia de la presencia de prospectores-mineros argáricos en el Noroeste en busca de estaño (Sierra, 1976: 56). Actualmente es interesante tener en cuenta nuevos elementos: dos punzones de Guidoiro Areoso y una gota de fundición de O Fixón-Costa da Seixeira. 
Los punzones, a excepción de los localizados en el yacimiento de Guidoiro Areoso, son una clase morfológica ausente en Galicia, aunque sí se han documentado en asentamientos del Norte de Portugal y también en la cornisa cantábrica. Su estudio tecnológico demuestra que se trata de piezas de bronce de buena calidad, con una composición $\mathrm{Cu}+\mathrm{Sn}$ y cierto contenido en As muy similar en ambas piezas (los portugueses y cántabros son de cobre). El punzón 1 fue conformado a martillo en frío sobre un yunque, y luego recocido para eliminar las tensiones del metal. Dado el contexto arqueológico ya comentado en el que aparecieron, y si se mantiene una datación de finales del III milenio a.C., nos encontraríamos ante dos piezas de bronce excepcionalmente prematuras en la Península Ibérica. Al menos en este caso, la vinculación con el Sureste debería ponerse en duda, ya que no se comienza a fabricar objetos de bronce hasta momentos avanzados de la cultura del Argar y los punzones calcolíticos del Sureste no presentan recocidos de este tipo (Montero, 1994: 288, 267).

Más sorprendente aún es la aparición de una gota de fundición en el yacimiento O Fixón-Costa da Seixeira, cuyo análisis determinó la presencia de bronce, ya que si en el primer caso podríamos pensar en una importación, en éste se trata de un indicio de producción local que demostraría la fundición in situ de bronce dentro de una cronología 1700-1500 a.C. (Suárez, 1993: 60). La hipótesis de una introducción de esta técnica en la Península Ibérica por vía atlántica de Norte a Sur va tomando entidad con estos hallazgos, cuya posición litoral queremos remarcar, aunque deba ser completada con otros para ser concluyentes.

Otros deben ser desmentidos, como la supuesta aleación $\mathrm{Cu}+\mathrm{Sn}+\mathrm{Pb}$ de un puñal de lengüeta de A Bastida (Pantón, Lugo) (Eiroa, 1973: 52). Hemos contrastado este análisis con el realizado en los laboratorios de Stuttgart (Junghans et alii, 1968: $\left.n .^{\circ} 7558\right)$, resultando notoria la diferencia en cuanto al porcentaje de Sn $(20,5 \%$ el primero y 0,25 el segundo), así como incierta la presencia de $\mathrm{Pb}$, por lo que creemos que se trata de un error. Respecto a las puntas tipo «Palmela», si bien alguna ha sido considerada de bronce, como las de Veiga dos Mouros (Monteagudo, 1954: 78), los análisis recientemente realizados indican que son todas de cobre.
La relación con el Sureste argárico se ha mantenido también para la aparición de las espirales de plata en el Noroeste, que varios autores sincronizan con las de la primera fase del Argar (Hernando, 1983: 123; Ruiz-Gálvez, 1979: 158; Almagro, 1976: 475; Sierra, 1976: 213). Además de las pertenecientes a cistas sin túmulo gallegas (Atios, Chedeiro) y el aro con cadenas de espirales de Antas de Ulla, en el Norte de Portugal se han localizado: en el interior de la cámara violada de Outeiro de Cregos I (Baião), en cuya estructura periférica apareció un vaso troncocónico con asa, decorado con mamelones; en la zona violada del túmulo pétreo de Meninas do Crasto IV (Baião); y en la base de una de las lajas de la Mamoa do Monte da Cerca (Esposende) (Jorge, 1986: 865). También se documentan espirales y anillos de cobre, de oro y cadenas formadas por espirales de oro. El análisis de las espirales portuguesas señala que son obtenidas a partir de plata nativa, cuya existencia en el subsuelo noroccidental permite plantear la posibilidad de una producción local, al menos de algunas de estas espirales de analogía formal con las argáricas discutible. Por ello es necesaria una profunda revisión de este tema, que debe considerar conjuntamente nuestra información sobre Galicia con la del Norte de Portugal y otras áreas limítrofes (20).

Otro conjunto que espera ser revisado es el de Caldas de Reis. Bouza Brey (1942: 193-194) publicó inmediatamente a su hallazgo la descripción más acertada sobre su producción, haciendo alusión al uso de la fundición. Ruiz-Gálvez (1978) publica la versión más conocida, que lamentablemente presenta algunos errores, tanto sobre las circunstancias, como en algunas medidas. Estima que las piezas fueron obtenidas por martillado, siguiendo la versión de Monteagudo (1953: 308). Además de resultar más acorde con la cronología que propone (fines del Bronce Antiguo), le permite establecer paralelismos tecno-formales con piezas inglesas como la jarra de Rillaton, obtenida por repujado (Ruiz-Gálvez, 1984: 180). Hernando (1983) recoge este estudio, incorporando este conjunto al resto de la orfebrería del Calcolítico y Bronce Antiguo. La última revisión tecnológica realizada por Armbruster y Perea (1994: 80) demuestra

(20) Trabajo que estamos desarrollando en nuestra tesis doctoral "Los inicios de la metalurgia en el Noroeste de la Península Ibérica", dirigida por J.M. Vázquez Varela. 
que las piezas han sido obtenidas por fundición mediante "cera perdida". Si mantenemos la cronología de fines del Bronce Antiguo para este conjunto, hemos de pensar en la primacía de la utilización de esta técnica en el Noroeste, que después podremos ver desarrollada en los brazaletes gallonados, o los de imitación al estilo Villena-Estremoz datados por las mismas autoras en un momento más avanzado. Por otro lado, la decoración de los vasos obtenida mediante un punzón u objeto cortante fino y duro (¿bronce?) podría hacer pensar en la posibilidad de suponer para Caldas de Reis una cronología más tardía, aunque debemos esperar la pronta publicación de su estudio tecnológico completo.

Para terminar sólo añadir que en el Noroeste de la Península Ibérica, como en otras partes, a la metalurgia le ha sido concedido un importante papel cultural que debe ser revisado, tanto por la vía analítica (sin negar sus limitaciones) como por la evaluación global de los contextos culturales que se hallan implicados. Al mismo tiempo la minimización de la relevancia de la metalurgia como explicación causal de la dinámica argárica en el Sureste y toda la reflexión teórica subsiguiente, constituye un buen punto de partida para la revalorización de la importancia de la difusión y asimilación de estímulos en el Noroeste, tanto de procedencia meridional como del área atlántica.

\section{BIBLIOGRAFÍA}

Almagro Gorbea, M. (1976): «La espada de Entrambasaguas. Aportación a la secuencia de las espadas del Bronce en el Norte de la Península Ibérica». XL Aniversario del Centro de Estudios Montañeses: 453-477. Santander.

Almeida Bautista, M.; Bóveda Fernández, Maj. y VIlaseco VÁzouez, X.I. (1995): «Galicia Different Place: Da cronoloxía do ouro precastrexo e outros tópicos». Historia Nova, III, Santiago: 25-33.

Álvarez Carballido, J. (1907): «Protohistoria. Ligera contribución al estudio de cobres y bronces de la región gallega conocidos por el nombre de célticos». Boletín de la Real Academia Gallega, I-II, 9: 197-202.

Álvarez Limeses, G. (1936): «Provincia de Pontevedra». En «Geografía General del Reino de Galicia». Carreras y Candi. Barcelona.

Armbruster, B. y Perea, A. (1994): «Tecnología de herramientas rotativas durante el Bronce Final Atlántico. El Depósito de Villena». Trabajos de Prehistoria, 51, 2: 69-87.

Bettencourt, A.M.S. (1995): «Dos Inícios a os Finais da Idade do Bronze no Norte de Portugal». En A Idade do
Bronze en Portugal. Discursos de Poder. Secretaría de Estado da Cultura. Lisboa: 110-115.

Bl.As CortiNa. M.A. de (1987): "Los primeros testimonios metalúrgicos en la fachada atlántica septentrional de la Península Ihérica". El origen de la metalurgia en la Peninsula Ibérica (Seminario organizado por la Fundación Ortega y Gasset, Oviedo 1987). Instituto Universitario Ortega y Gasset. Universidad Complutense de Madrid. II: 66-96.

Bouza BREY. F. (1942): "El peine de oro del Tesoro Prehistórico de Caldas de Reyes". Boletín de la Real Academia Gallega. XXIII, 269-270: 187-203.

COMENDAIJOR REY. B. (1991-2): "Los inicios de la metalurgia: primeros testimonios de la provincia de Pontevedra». Brigantium. 7: 185-204. Museu Arqueolóxico e Histórico. La Coruña.

- (1993): "Sobre la presencia de aluminofosfatos y otros minerales en la provincia de Pontevedra". Actas del XXII Congreso Nacional de Arqueología (Vigo 1993), I: $63-68$.

Criado. F.: Bonilla. A.: Cerqueiro, D.; Diaz. M.; Gonzalez. M.; Infante. F.; Méndez. F.; Penedo, R.; Rodriguez. E. y Vaquero. J. (1991): Arqueología del Paisaje. El área Bocelo-Furelos entre los tiempos paleolíticos y medievales. Arqueoloxía Investigación, 6. Xunta de Galicia. Santiago de Compostela.

Criado Boado, F.: Ramil Soneira, J. y Vázquez Vare. LA, J.M. (1981): "Nuevos hallazgos de campaniforme en la provincia de Lugon. Cuadernos de Estudos Galegos, XXXII: 455-466.

Criado Boado. F. y Vázouez Varela, J.M. (1980): la cerámica campaniforme en Galicia. Cuadernos de Estudos do Seminario de Sargadelos, 42. La Coruña.

DElibEs, G. y FERnÁNDEZ-MirANDA, M. (1993): "Los origenes de la civilización. El Calcolítico en el Viejo Mundo». Colección Historia Universal-Prehistoria. Editorial Síntesis. Madrid.

EIrOA. J.J. (1973): «Análisis metálicos sobre útiles de bronce gallegos». Estudios del Seminario de Prehistoria, Arqueologia e Historia Antigua de la Facultad de Filosofía y Letras de Zaragoza, II: 49-55.

FÁbregas VAlCarce, R. y Ruiz-Gálvez, M. (1994): "Ámbitos funerario y doméstico en la Prehistoria del Noroeste de la Península Ibérica». Zephyrus, XLVI: 143-159.

Filgueira Valverde, J. y García Alén, A. (1978): «Adiciones a la Carta Arqueológica de la provincia de Pontevedra». El Museo de Pontevedra, XXXI: 51-130. Pontevedra.

García Alén, A. (1970): "Adquisiciones del Museo de Pontevedra». El Museo de Pontevedra, XXIV: 37-47.

García Martínez, M. C. (1980): «Galicia Eterna», Barcelona.

HARRISON, R. J. (1974)a: «Ireland and Spain in the Early Bronze Age. Fresh evidences for Irish and British contacts with Proto-Atlantic Bronze Age Spain in the second millenium B.C.". Journal of the Royal Society of Antiquaries of Ireland, 109: 58-60.

- (1974)b: «A closed find from Cañada-Rosal near Écija (Prov. Sevilla) and Two Bell Beakers». Madrider Mitteilungen, XV: 77-94. 
Harrison. R.J.: Craddock. P.T. y Highes. S.J. (1981): "A study of the Bronze Age metalwork from the lberian Peninsula in the British Museum". Ampurias, 4.3. 11.3-179.

Hernando Gonzalo. A. (1983): «La orfebrería durante el Calcolítico y el Bronce Antiguo en la Península Ibérica». Trabajos de Prehistoria, 40: 86-138.

"Inventario do Museu Nacional de Arqueología" (1993). Colecção de Ourivesaría. $1^{\circ}$ volume, Do Calcolítico á Idade do Bronze. Lisboa.

Jorge, S. Oliveira (1986): «Povoados da Pré-Historia recente da Regiao de Chaves- $V^{a}$. $P^{a}$. de Aguiarm. Instituto de Arqueología da Facultade de Letras do Porto. Porto.

Junghans, S.; SANGmeister. E. y SChröder. M. (1968): Metallanalysen Kupferzeitlicher und Frübonzezeit Bodenfunde aus Europa. S.A.M. II Geb. Mann Verlag. Berlín.

López Alonso CUEVILl.AS. F. (1925): «Os oujetos argáricos do Museu D'Ourense». Boletín de la Real Academia Gallega. XV: 96-107.

- (1933): "Terra de Melide». Seminario de Estudios Gallegos. Santiago.

- (1955): «El comienzo de la Edad de los Metales en el Noroeste. Peninsular». Cuadernos de Estudos Galegos, $\mathrm{X}: 5-41$.

LÓPEZ FERnÁNDEZ. E. (1992): "As mámoas do Concello de Fonsagrada". Boletín del Museo Provincial de Lugo, $\mathrm{V}: 105-117$

MACIÑEIRA PARdo DE LAMA. F. (1941): «El vaso campaniforme y condiciones de sus intactos yacimientos tumulares en la estación de Puentes, del Cabo Ortegal». Atlantis, XVI, 3-4: 356-369.

- (1943): «Túmulos prehistóricos. Inventario descriptivo de los 286 túmulos prehistóricos hasta ahora descubiertos en la avanzada comarca de Cabo Ortegal». Boletín de la Real Academia Gallega, XXIV: 15-68.

Meijide Cameselle, G. (1989): «Un importante conjunto del Bronce Inicial en Galicia: El Depósito de Leiro (Rianxo, A Coruña)». Gallaecia, XI: 151-164. Santiago de Compostela.

MÉNDEZ FERNÁNDEZ. F. (1994): «La domesticación del paisaje durante la Edad del Bronce Gallego». Trabajos de Prehistoria, 51: 77-94.

Monteagudo. L. (1953): «Orfebrería del Noroeste Hispánico de la Edad del Bronce". Archivo Español de Arqueología, XXVI: 269-312.

- (1954): «Metalurgia hispana de la Edad del Bronce con especial estudio de Galicia y Norte de Portugal». Caesaraugusta, IV: $55-95$

- (1977): Die Beile auf der Iberischen Halbinsel. Prähistorische Bronzefunde, IX, 6. Munich.

MONTERO RUIZ. I. (1994): «El Origen de la Metalurgia en el Sureste de la Península Ibérica». Instituto de Estudios Almerienses. Almería.

Murguía, M. (1988): «Historia de Galicia». Editorial Gran Enciclopedia Vasca (1979), I. Santiago.

ONTAÑón PEREDo, P. (1994): «El neolítico final-calcolítico en Cantabria». Actas del $1^{\circ}$ Congreso de Arqueología Peninsular (Oporto, 1993). Trabalhos de Antropología e Etnología, III: 134-151.
Peva Santos. A. de l.a (1984): "Yacimiento de Lavapés (Cangas). Balance de las excavaciones 1981-1982". Pontevedra Arqueológica, I: 149-177. Pontevedra.

Peña Santos. A. de l.a y Rfy Garcia. J.M. (1993): "El espacio de la representación. El arte rupestre galaico desde una perspectiva territorial». Pontevedra. Revista de Estudios Provinciais, 10: 10-50. Diputación de Pontevedra. Pontevedra.

Pérez Bustamante. C. y Parga Pondal. S. (1924): "Notas de Arqueología Prehistórica Galaica. Los dólmenes de Dombate y la Gándara (La Coruña)». Boletín de la Biblioteca Menéndez Pelayo. Santander.

Prieto Martinez. P. (1993): "Definición de un sistema metodológico para el estudio de la cerámica de la Edad del Bronce en Galicia: la tradición campaniforme del yacimiento de A Lagoa (Toques, A Coruña)". Actas del XXII Congreso Nacional de Arqueología (Vigo 1993). II: $17-24$.

Rey Garcia, J.M. (1991): "Guidoiro Areoso (Vilanova. Pontevedra)". Arqueoloxia. Informes. 1988: 29-30. Santiago.

RodRíguez CASAL. A. (1989): La necrópolis megalítica de Parxubeira. Monografías Urxentes do Museu. 4. Museo Arqueolóxico e Histórico de A Coruña.

Rovira, S. y MONTERO, I. (1994): "La metalurgia». En M ${ }^{a}$ Concepción Blasco (ed.): «El Horizonte Campaniforme en la región de Madrid en el Centenario de Ciempozue. los». Universidad Autónoma. Madrid: 137-172.

Ruiz-GÁlvez Priego, M. (1978): «El Tesoro de Caldas de Reyes». Trabajos de Prehistoria, 35: 173-192.

- (1979): «El Bronce Antiguo en la Fachada Atlántica Peninsular. Un ensayo de periodización». Trabajos de Prehistoria, 36: 153

- (1984): «La Peninsula Ibérica y sus relaciones con el Circulo Cultural Atlántico». Colección Tesis Doctorales. Universidad Complutense de Madrid. Madrid.

- (1987): «Bronce Atlántico y "cultura" del Bronce Atlántico en la Península Ibérica». Trabajos de Prehistoria, 44: 251-264. Madrid.

SierRA Rodríguez. J.C. (1976): «Novo machado plano da provincia de Ourense». Boletín Auriense, VI: 49-56. Orense.

Sobrino Lorenzo-RuZA, R. (1952): "Origen de los petroglifos gallegos atlánticos». Zephyrus, III: Salamanca.

SuÁrez OTERO. J. (1993): «O Fixón: Una nueva perspectiva del Bronce Inicial en Galicia». Actas del XXII Congreso Nacional de Arqueología (Vigo, 1993), II: 57-68.

VAquero LAstres, J. (1993): "Túmulos del NW: Escenas». Actas del XXII Congreso Nacional de Arqueología (Vigo, 1993), I: 39-45.

VÁZQUEZ VARELA. J.M. (1980): «Enterramientos en cista de la Edad del Bronce en Galicia». Pontevedra, 0: 23 40. Pontevedra.

- (1992): «Las más viejas raíces de Galicia». Biblioteca, 114: 55. Biblioteca del Correo Gallego. Santiago.

VILlAamil y CASTRO, J. (1906-1907): «Productos de la metalurgia gallega en tiempos remotos». Boletín de la Comisión Provincial de Monumentos Históricos y Artís. ticos de Orense, III, 53: 82-161. 